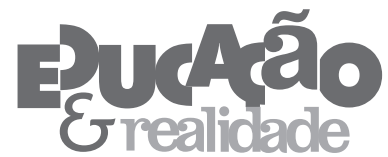

\section{Imagens da Prisão Feminina: ilustrações presentes no jornal Só Isso!}

Daiane de Oliveira Tavares

RESUMO - Imagens da Prisão Feminina: ilustrações presentes no jornal Só Isso! Tendo como fonte/ objeto de pesquisa o jornal - Só Isso! - produzido por apenadas na Penitenciária Talavera Bruce, situada no Rio de Janeiro, o objetivo deste trabalho é investir na análise de algumas de suas imagens, refletindo acerca da importância destas, na medida em que trazem maior sentido à escrita do impresso e se tornam um meio de interlocução entre os leitores e autores. A partir dessa interpretação, é possível pensar os sentidos da escrita e ilustrações oriundas da prisão a fim de ampliar a compreensão de discursos e práticas de privados de liberdade, dando visibilidade às suas vozes e às suas tentativas de constituição de um elo com um mundo entre grades, para além dos muros da prisão.

Palavras-chave: Imagens. Privação de Liberdade. Mulheres. Escrita.

ABSTRACT - Images of Women's Prisons: illustrations in the Só Isso!newspaper. The newspaper - Só Isso! - made by the inmates of the Talavera Bruce prison in Rio de Janeiro is the source for this research, the main object of this work is to analyze on the importance of some of their images, since by this we can make more sense of their writings.This method of observation based on both the illustrations and writings made inside, allow us to have a better understand of the inmate's life, also giving a voice for their attempts to dialog their inner thoughts with the outside world.

Keywords: Image. Deprivation of Liberty. Women. Writing. 


\section{Apresentando o Só Isso!}

Em meio a uma grande festa, foi lançado no dia 2 de julho de 2004, o periódico Só Isso! inteiramente redigido e ilustrado por mulheres privadas de liberdade na Penitenciária Talavera Bruce, localizada no estado do Rio de Janeiro, no Complexo de Gericinó, antigo Complexo de Bangu. Esse projeto partiu da iniciativa de quatro mulheres: Lotta Hagstrom uma finlandesa, a alemã Sabrina Hagel, a boliviana Lila Mirtha e a brasileira Marileine. Na formação inicial da equipe, Sabrina era a editora do impresso, Lila e Marileine atuavam na redação do jornal e Lotta elaborava suas ilustrações.

Trata-se de um jornal colorido, ilustrado (com fotos, tabelas, imagens diversas) e, para executarem esse projeto, as internas da Talavera contaram com o patrocínio de empresas extramuros que junto as apenadas idealizaram e fizeram com que os jornal circulasse durante 4 anos nos presídios do estado do Rio de Janeiro.

Diante desse objeto/fonte de pesquisa este artigo tem como objetivo destacar as ilustrações trazidas no Só isso!, tendo em vista que “[...] a imagem no frontispício ou na página do título, na orla do texto na sua última página, classifica o texto, sugere uma leitura, constrói um significado. Ela é protocolo de leitura, indício identificador" (Chartier, 2002, p. 133). Outra questão relevante é atentar para o que sugere Sierra Blas (2003, p. 83) ao destacar que "[...] la imagen, siempre que sea bien elegida, tiene el poder de mostrar lo que la palabra no puede enunciar"1.

Nesse sentido, os desenhos contidos no jornal são uma importante fonte de análise, principalmente por terem sido, segundo informan$\mathrm{te}^{2}$ envolvido com o projeto, um dos motivos que geraram tensões entre a equipe do jornal e a Direção da Unidade.

Figura 1 - Exemplares do Jornal Só Isso!

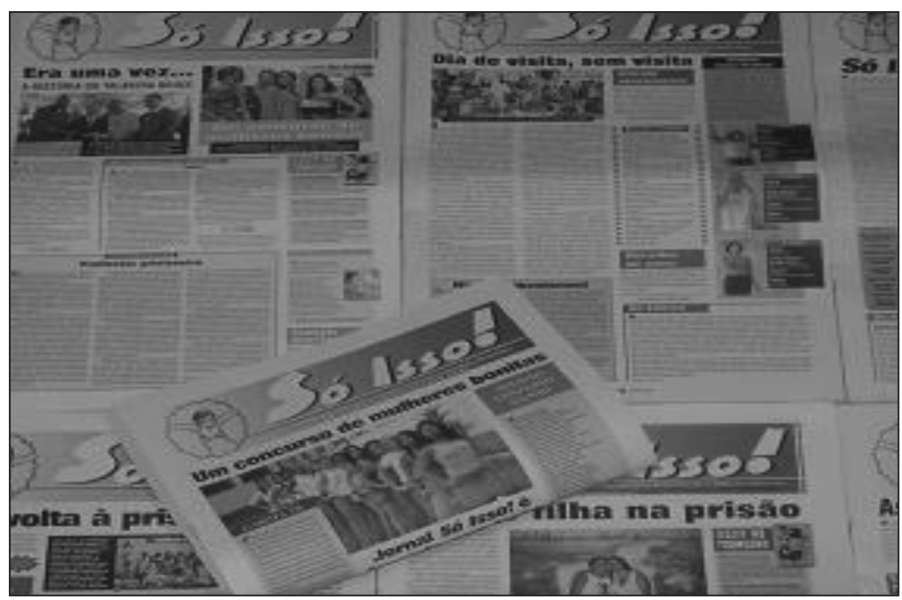

Fonte: Elaborado pela autora. 
Durante o período em que o impresso circulou foram lançadas 13 edições, conforme o quadro abaixo, distribuído em todos os presídios do Rio de Janeiro e de outros estados, além de circular em órgãos públicos e instituições.

Quadro 1 - Relação de exemplares do Jornal Só Isso!

\begin{tabular}{|c|c|c|}
\hline Ano e Número & Data & Número de Páginas \\
\hline $1 / 1$ & Maio de 2004 & 08 \\
\hline $1 / 2$ & Agosto de 2004 & 08 \\
\hline $1 / 3$ & Outubro de 2004 & 08 \\
\hline $1 / 4$ & Dezembro de 2004 & 08 \\
\hline $2 / 5$ & Março de 2005 & 08 \\
\hline $2 / 6$ & Maio de 2005 & 08 \\
\hline $2 / 7$ & Agosto de 2005 & 12 \\
\hline $3 / 8$ & Janeiro de 2006 & 12 \\
\hline $3 / 9$ & Maio de 2006 & 12 \\
\hline $3 / 10$ & Setembro de 2006 & 12 \\
\hline $3 / 11$ & Dezembro de 2006 & 12 \\
\hline $4 / 12$ & Agosto de 2007 & 12 \\
\hline $5 / 13$ & Agosto de 2008 & \\
\hline
\end{tabular}

Fonte: Edições do Só Isso! Elaborado pela autora.

A possibilidade de organização das mulheres presas em prol da produção de um jornal reveste-se de grande relevância no sentido de criar um espaço de comunicação e trabalho, pois como aponta Antonio Nóvoa (2002, apud Catani; Bastos, 2002), a imprensa periódica é lugar de permanente regulação coletiva: a elaboração de um jornal traz sempre debates e discussões, polêmicas e conflitos; mesmo quando é fruto de uma vontade individual, a controvérsia não deixa de estar presente, no diálogo com os leitores, nas reivindicações junto aos poderes públicos ou nos editoriais de abertura.

Para as internas da Penitenciária Talavera Bruce, o Só Isso!, como se lê no editorial da segunda edição do jornal:

[...] representa um grande acontecimento e um veículo importante de informação e, a partir dele, a sociedade poderá saber e lembrar que, ao serem presas, elas não dei-

Educação \& Realidade, Porto Alegre, v. 38, n. 1, p. 137-153, jan./mar. 2013.

Disponível em: <http://www.ufrgs.br/edu_realidade> 
Imagens da Prisão Feminina

xam de ser seres humanos com sentimentos, esperanças e valores (n. 2, ago. 2004, p. 03).

O Só Isso! teve grande repercussão na mídia, pois contou com o patrocínio de empresários ${ }^{3} \mathrm{e}$, ainda, de um jornalista que treinava as internas em texto, reportagem, edição e diagramação. Na internet é possível encontrar diversas matérias sobre o periódico, veiculadas por grandes jornais e revistas como a Folha de São Paulo e a Revista Época.

Segundo informações da Folha de São Paulo ${ }^{4}$, Lila Mirtha é dentista e foi presa em 1999, em seu apartamento em Botafogo, na Zona Sul da cidade do Rio de Janeiro. Ela era a responsável pelos textos. Divorciada, tinha dois filhos. Lotta Hagstrom é artista plástica e foi presa em 2002 no aeroporto internacional do Rio de Janeiro quando levava cocaína para o seu país. Marileine é professora, também condenada por tráfico e cuidava da publicidade. Em outubro de 2002, Sabrina Hagel foi presa quando tentou levar do Brasil para Alemanha 10 quilos de cocaína. Também casada e com dois filhos. No Só Isso!, Sabrina conta um pouco mais de sua história:

Quando eu escolhi o dinheiro não pensei nas consequências. Tenho 25 anos, fui presa junto com minha mãe por tráfico internacional de entorpecentes. Infelizmente pegamos uma pena de quatro anos, que é a sentença mínima, mas para nós é máxima (Só Isso!, n. 06, maio 2005, p. 06).

O fato de se sentirem abandonadas, solitárias, devido à distância de seu país de origem, além da dificuldade de conseguir trabalho durante o cumprimento da pena por conta de sua nacionalidade, podem ter sido os motivos que levaram estas mulheres a idealizar e concretizar esse projeto:

O jornal Só Isso! será um veículo para a criação de trabalho dentro do Sistema. Muitos verão que nós, internas, necessitamos de trabalho para ocupar o nosso tempo, adquirir conhecimento e aprender uma profissão. O trabalho prisional é fundamental para a recuperação e ressocialização do ex-presidiário na sociedade. Todas nós, internas, não só do Talavera Bruce, mas também de outras unidades prisionais, contamos com a concretização de nossos projetos e ideias, e o principal é o trabalho dentro dos presídios! (Tavalera Bruce - Editorial, n. 02, ago. 2004, p. 01).

O relato encontrado na pesquisa coordenada por Bárbara Soares ajuda a pensar na realidade das mulheres estrangeiras aprisionadas em nosso país:

M. tem 26 anos, é estrangeira e queria conhecer o Brasil, além de ganhar dinheiro. Foi presa com o marido, que acabou sendo morto pela polícia, quando viajavam com passaporte falso. Sente-se duplamente desrespeitada em 
seus direitos: 'Não recebemos nenhuma visita [...]. Trabalhar é muito difícil, pois não chamam as estrangeiras' (Soares, 2002, p. 96).

Trazer a materialidade e temas destacados no Só Isso! propicia pensar os sentidos dessa escrita na prisão, permitindo também compreender o veículo utilizado, seu suporte, que nesse caso é um jornal, pois "não existe texto fora do suporte que o dá a ler, que não há compreensão de um escrito, qualquer que ele seja, que não dependa das formas através das quais ele chega ao seu leitor" (Chartier, 2002, p. 127). Além disso, é preciso "compreender as séries de discursos na sua descontinuidade, desmontar os princípios de sua regularidade, identificar as suas racionalidades particulares [...]" (Chartier, 2002, p. 133).

Diante dessa perspectiva, vale destacar que para dar conta de diversos assuntos, o jornal possui seções fixas em suas edições, que são: Aconteceu, virou só isso!; Recados de Amor; Uma de Nós; Compra, venda e serviços; Pingue e Pongue; História de vida; Religião, Espiritualidade e Fé; O que precisamos saber: Assistência Jurídica e Saúde; Correio Sentimental; Boca no Trombone; Carta de Leitores e Coluna da Tereza.

Diante de todas essas seções ${ }^{5}$, é possível perceber que o jornal traz muitas "informações próximas do fato ou acontecimento recente, ou seja, os escritos jornalísticos têm um caráter mais imediato, inscrevendo-se numa lógica de reação a acontecimentos ou ideias, normas legais, situações políticas e outras circunstâncias" (Fernandes, 2008, p. 19).

A compreensão acerca da diversidade de seções e temáticas do jornal, segundo Magaldi e Xavier (2008), oferece ao pesquisador a investigação de um universo amplo e abrangente, em que é possível perceber práticas diversas, assim como ideias produzidas e disseminadas por múltiplos agentes.

Diante da diversidade de assuntos e questões abordadas no Só Isso! este impresso se configura em meio extremamente útil para interpretar as relações entre os projetos e as realidades, entre a tradição e a inovação, características próprias da imprensa (a proximidade em relação ao acontecimento, o caráter fugaz e polêmico, a vontade de intervir na realidade) que lhe conferem este estatuto único e insubstituível” [...] (Nóvoa apud Dias, 2002, p. 113).

Nesse sentido, buscarei a partir de agora, trazer uma análise de algumas das\ilustrações presentes no periódico a fim de perceber o que estas podem revelar acerca da realidade vivida pelas privadas de liberdade.

\section{Ilustrações do Impresso de uma Prisão Feminina}

As ilustrações contidas no Só Isso! trazem à tona sentimentos expressados em desenhos diversos que mostram o quanto essas mulheres vislumbram a liberdade, encontrar um amor e muitas vezes parecem 
traduzir saudade e solidão. São muitas as imagens de pássaros, corações, flores, entre outras que nada remetem ao ambiente frio e hostil da prisão.

Figura 2 - Ilustração

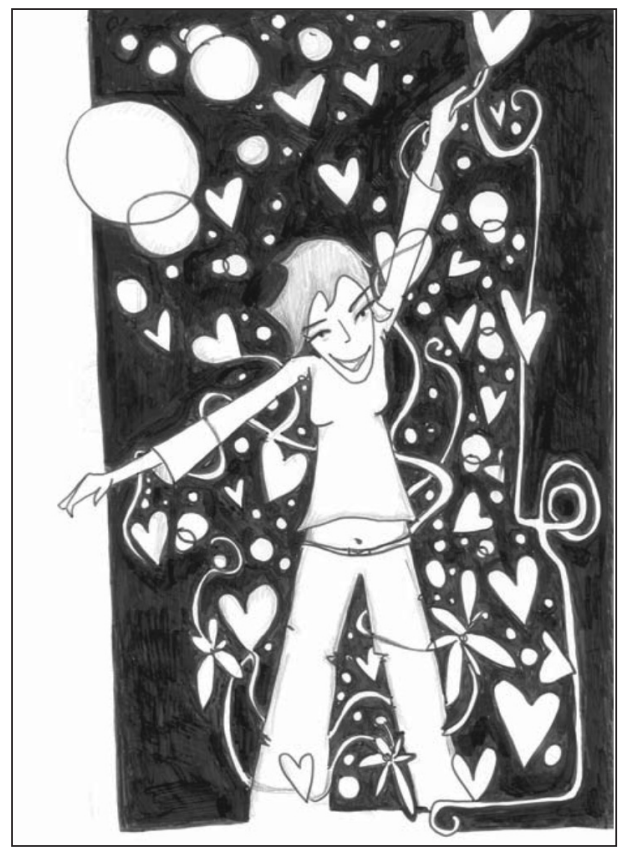

Fonte: Só Isso!, edição n. 3, out. 2004, p. 05.

Essas ilustrações permitem pensar nas práticas que produzem esse impresso e os usos que deles são feitos, atentando para os dispositivos textuais e tipográficos de produção de sentido e as estratégias que os produzem e os põem em circulação. "Com efeito, cada forma, cada suporte, cada estrutura da transmissão e da recepção do escrito afeta profundamente seus possíveis usos e interpretações" (Chartier, 2003, p. 44).

Nessa perspectiva, é possível pensar que a ilustração é um recurso que, aliado à escrita, ajuda a esses sujeitos a expressarem seus sentimentos, amenizado assim, as dores causadas pela vida no cárcere e, ainda, traz para o impresso uma aparência agradável e muito diferente das angústias e dificuldades da vida das encarceradas.

Conforme Chartier (2002, p. 133), as ilustrações trazidas no Só isso! podem muito dizer sobre esse impresso e sobre suas escritoras. Nesse sentido, os desenhos contidos no jornal são uma importante fonte de análise, principalmente por terem sido, como já dito, um dos motivos que geraram tensões entre a equipe do jornal e Direção da Unidade, 
após a saída do Diretor que incentivou a criação do jornal. Tal fato leva à reflexão ao que aponta Chartier (2002, p. 137), quando diz que "não há produção cultural que não empregue materiais impostos pela tradição, pela autoridade ou pelo mercado e que não esteja submetida às vigilâncias e às censuras de que tem poder sobre as palavras ou gestos”. Segundo o referido informante, a conotação homossexual de algumas ilustrações e textos do impresso geraram problemas que contribuíram para o fim do Só Isso! em 2008. As ilustrações que seguem são exemplos do exposto:

Figura 3 - Ilustração

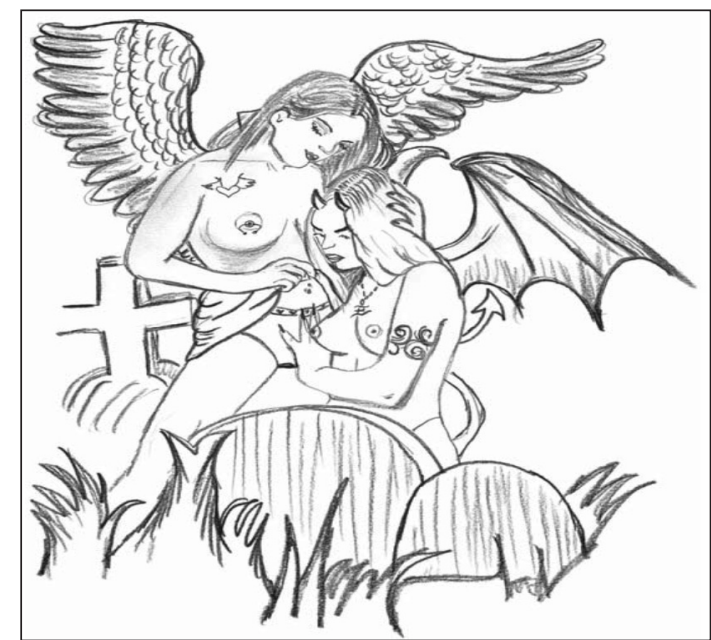

Fonte: Só Isso!, arquivo digital da edição n. 10, set. 2006, p. 01.

Figura 4 - Ilustração

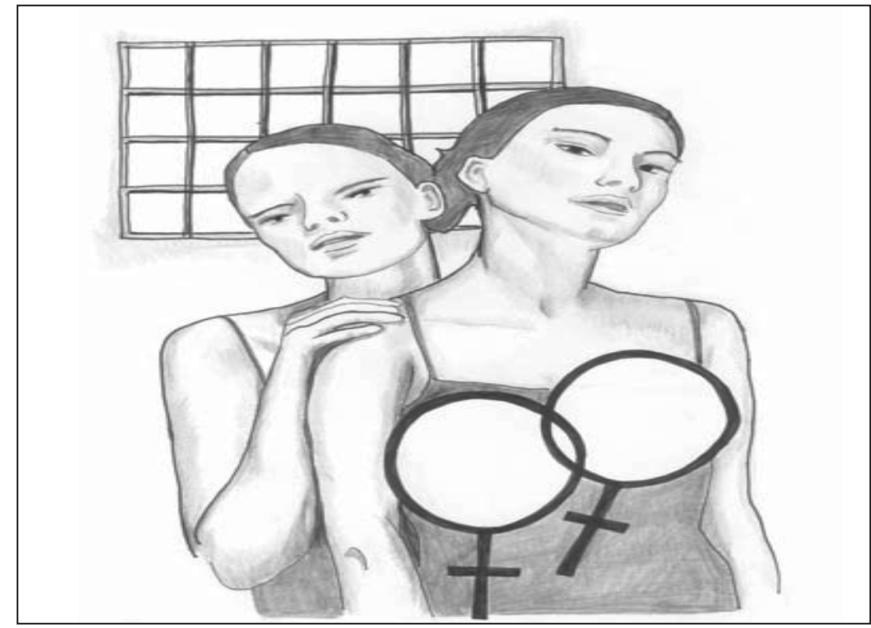

Fonte: Só Isso!, arquivo digital da edição n. 3, out. 2004, p. 01.

Educação \& Realidade, Porto Alegre, v. 38, n. 1, p. 137-153, jan./mar. 2013.

Disponível em: <http://www.ufrgs.br/edu_realidade> 
Imagens da Prisão Feminina

Tal fato nos leva a refletir sobre o que nos aponta Bárbara Soares e Iara Ilgenfritz (2002, p. 43) acerca das questões referentes à sexualidade em um presídio feminino:

\begin{abstract}
Com relação à manifestação sexual- uma necessidade primária do ser humano-, a lei é omissa. De modo geral, a questão da sexualidade nos presídios é tratada com muita hipocrisia: a liberdade sexual do mundo de hoje se contrapõe frontalmente aos preconceitos, tabus e julgamentos morais que regem a sexualidade dentro da prisão.
\end{abstract}

A vida no cárcere faz com que essas mulheres expressem a sua sexualidade das maneiras mais contraditórias e criativas, apesar de todo cunho moralizante e preconceituoso que reveste uma instituição penal feminina. A sexualidade e a homossexualidade ainda são vistas com muito preconceito pelos responsáveis por um presídio para mulheres e, prova disso, foi a censura em relação às ilustrações contidas no Só Isso!, que expressavam essa questão. "A partir do momento em que a interna é definida como homossexual pela administração e pelo corpo de guardas, ela estará sujeita à observação constante [...]" (Lemgruber, 1999, p. 119).

No entanto, o Só Isso! abriu espaço para que casais homossexuais contassem suas histórias e enviassem recados apaixonados. A figura de número quatro está na capa da edição de número três para destacar a entrevista entre Cris e Paula que formam um casal homossexual e que se conheceram antes mesmo de serem presas. Já na seção "Recados de Amor" existem trocas de textos amorosos entre mulheres, como nos mostra um trecho de Biscuti para Érica, ambas internas da Talavera Bruce:

Que há então de mais na decisão que tomei? Descobri que eu pensava erradamente acerca de declarar meu amor por ti. Pensava eu que se repetisse muitas vezes que "te amo" as palavras começariam a soar repetitivas, vazias, desprovidas de verdade e de emoção (Só Isso!, n. 9, mai. 2006, p. 09).

Um recado de Cris para Paula demonstra explicitamente a relação homossexual das duas apenadas e, inclusive, a remetente se expressa como se fosse do sexo masculino:

Minha galega! Fico feliz por nós. Pois dia 18 de dezembro comemoraremos seis anos de casamento. Espero que o que sentimos um pelo outro se renove a cada ano. Sei que não mereço tanto amor, e ter uma pessoa tão maravilhosa assim do meu lado me enche de orgulho e satisfação. Deixo aqui um pequeno recado, por esta data muito especial! Do seu negão que muito te ama (Só Isso!, n. 2, dez. 2004, p. 07). 
Diante desse cenário, para melhor compreender a relação sexual entre mulheres privadas de liberdade, vale destacar:

[...] a característica afetiva do feminino conduz muitas encarceradas, na ausência ou carência de relações heterossexuais sólidos, a homossexualidade como uma estratégia de adaptação e resistência às privações carcerárias; esta, não obstante em muitos casos, desencadeada por motivações distintas da orientação sexual já anteriormente existente, ou dos critérios típicos da homossexualidade nas prisões masculinas, reforça os estereótipos de inadaptabilidade aos padrões de "normalidade" (Chies; Barros; Lopes; Colares; Oliveira, 2009, p. 274).

A questão da homossexualidade nos presídios femininos tem como um dos seus motivos o abandono e a solidão presentes na vida dessas mulheres. Em pesquisa realizada por Julita Lemgruber (1999, p. 117) na Penitenciária Talavera Bruce, esta verificou que:

[...] levando-se em conta depoimento de internas, guardas e de pessoas da administração, grande número de presas envolve-se na prática homossexual - algumas esporadicamente, outras com maior frequência e constância.

Diante das questões aqui levantadas, o jornal Só Isso! revela muito o cotidiano de um presídio feminino, as dificuldades materiais, psicológicas e sentimentais por que passam esses sujeitos, discussões sobre o encarceramento, reivindicações e o sonho de algumas dessas mulheres de construírem melhores condições de vida dentro e além das grades da prisão. Nesse sentido, outra imagem bastante significativa e que remete às queixas e dificuldades enfrentadas por essas mulheres, diz respeito à ilustração que representa a seção "Boca no Trombone" que se caracteriza como o espaço em que as apenadas escrevem por melhores condições de vida:

Figura 5 - Ilustração

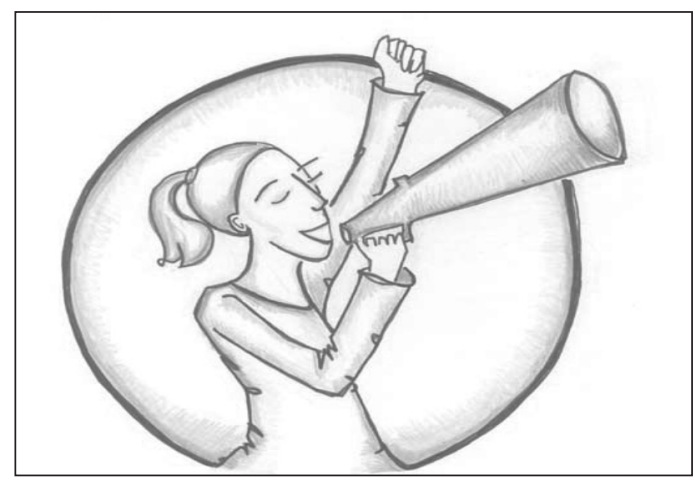

Fonte: Só Isso!, edição n. 02, ago. 2007, p. 07.

Educação \& Realidade, Porto Alegre, v. 38, n. 1, p. 137-153, jan./mar. 2013.

Disponível em: <http://www.ufrgs.br/edu_realidade> 
Imagens da Prisão Feminina

A referida seção abre um espaço onde as mulheres da Talavera Bruce lutam por seus direitos na prisão. Nesse espaço do jornal é possível perceber as muitas dificuldades e carências de uma Penitenciária feminina e como esses sujeitos, a partir da possibilidade de reivindicar por melhores condições de vida por meio do impresso, fazem com que este se torne um instrumento político e educativo.

Encontramos na seção a reivindicação por trabalho na prisão, pedidos de medicamentos, ambulância, médicos para a Unidade, cadeiras de rodas, agasalhos, camas para os alojamentos, cobertores, equipamentos para o consultório dentário, solicitação de fraldas para os filhos das apenadas que estão na creche da Penitenciária, entre outras:

\begin{abstract}
Alguns anos atrás quando os presos chegavam na unidade, eles recebiam um pequeno kit para manter-se com o mínimo de dignidade na prisão. Neste kit continham: uma caneca, um prato, uma colher e garfo plástico, um colchão, um lençol, um cobertor e duas camisas. Fora isso, recebiam mensalmente um kit de higiene contendo: uma barra de sabão, um litro de cloro, um sabonete, um creme dental, um rolo de papel higiênico e um pacote de absorvente. E agora? Falta tudo, não temos absolutamente nada. Hoje o nosso material de limpeza é água, somente água. Sem falar que não temos camas suficientes. Isso é um dever do estado... (Só Isso!, n. 12, ago. 2007, p. 01).
\end{abstract}

Um tema recorrente na seção "Boca no Trombone" é a falta de oferta de trabalho para as apenadas. Esse fato é bastante compreensível em um contexto em que quase metade das mulheres presas não têm acesso a atividades laborativas e não há uma política séria ligada ao trabalho prisional para atendimento das demandas desses sujeitos. Diante desse cenário, é fácil compreender o quanto essa questão motivou a criação do jornal e o grande apelo por trabalho que encontramos no impresso:

O jornal Só Isso! será um veículo para a criação de trabalho dentro do Sistema. Muitos verão que nós, internas, necessitamos de trabalho para ocupar o nosso tempo, adquirir conhecimentos e aprender uma profissão. $\mathrm{O}$ trabalho prisional é fundamental para a recuperação e ressocialização do ex-presidiário na sociedade (Só Isso!, n. 2, ago 2004, p. 01).

Nesse sentido, vale ressaltar o que nos aponta Chies e Varela (2007, p.10) ao refletir sobre o trabalho oferecido para as mulheres privadas de liberdade:

As manifestações, entretanto, não tendem a incluir significativas perspectivas de acesso ao mundo do trabalho formal. $\mathrm{O}$ artesanato, a costura, a faxina, a cozinha, sugerem mais uma "alternativa" de trabalho autônomo e precário do que uma efetiva possibilidade de emprego. 
No entanto, em nenhum momento as internas criticam o tipo de trabalho oferecido na prisão e ainda ressaltam que esse grupo representa mão de obra barata. No que tange à participação das empresas privadas no âmbito do trabalho prisional, vale atentar para as seguintes questões:

[...] nem sempre (e via de regra) a participação do setor privado no oferecimento de vagas de trabalho corresponde a uma perspectiva de alteração do cenário de exclusão social, ou mesmo de inclusão precária. Os "benefícios" concedidos pela legislação de execução penal à utilização de mão-de-obra prisional - não sujeição às garantias trabalhistas e ao regime da Consolidação das Leis do Trabalho artigo 28, $\$ 2^{\circ}$ da LEP), possibilidade de remuneração na fração 3/4 (três quartos) do salário mínimo (artigo 29, caput, da LEP) - as possibilidades de utilização gratuita, ou de baixo custo, da infra-estrutura do Estado (prédios, energia elétrica, etc.), e a tendencial motivação dos apenados para o trabalho (sobretudo em face da perspectiva da remição e como forma de "ocupar o tempo"), fazem da presença do setor privado mais uma expressão da exploração capitalista do que de um modo de co-participação ético-teleológica na perspectiva de inclusão social humano- dignificante (Chies; Varela, 2007, p. 11).

Diante desse cenário não é difícil perceber que o contexto carcerário evoca a desumanização dos sujeitos e, consequentemente, a desumanização do trabalho. Ao pensar o trabalho de internos como possível elemento de reconstrução de vida desses sujeitos, há que supor a existência de uma visão mais humanista de trabalho, pela qual os seres humanos sejam capazes de se ver como trabalhadores e interferir na realidade de maneira crítica.

Ao analisar os textos e as ilustrações contidas no jornal é possível perceber diversas questões ligadas as vicissitudes do encarceramento feminino e como essas mulheres buscam a partir do Só Isso! uma maneira de superar a solidão por meio da comunicação com o mundo intra e extra muros. A figura abaixo que ilustra a matéria intitulada "Diário de uma detenta" nos remete aos sentidos da escrita na prisão e a importância que esta assume no sentido de amenizar a tristeza e a mazelas causadas pela vida no cárcere, garantindo um espaço de desabafo para esses sujeitos. 
Figura 6 - Ilustração

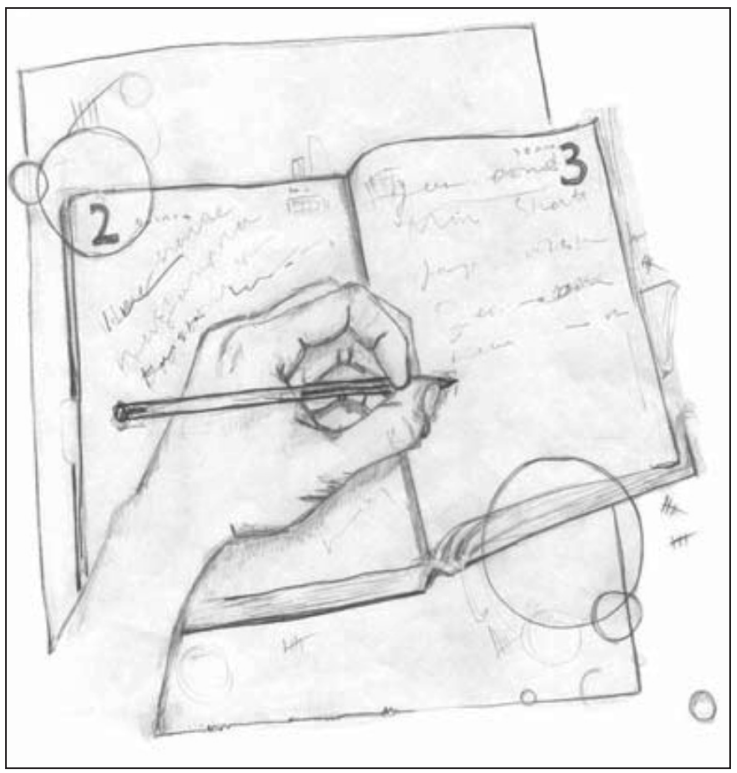

Fonte: Só Isso!, edição n. 04, dez. 2004, p. 01.

As dificuldades físicas e materiais que denotam a precarização das assistências e direitos aos privados de liberdade aliam-se à tristeza individual de cada interna que sofre em sua cela e desabafa por meio do Só Isso!. O trecho abaixo da referida matéria que acompanha a ilustração acima, expõe a dificuldade de estar enclausurada e a dificuldade de viver em um ambiente tão hostil e que não prepara para a vida além das grades:

O clarão do dia vem surgindo, chego até as grades para contemplá-lo, e isto aumenta mais o meu desejo de ser livre. O meu sol que já era pouco se tornou nenhum nesse cativeiro de sombras, onde a minha vida passa simplesmente por passar. Olho ao redor e vejo que nada mudou! É a mesma aparência morta de um cemitério. Talvez possam existir mortas-vivas como eu, enterradas na sombra do esquecimento pela fonte da realidade que é a 'Sociedade' (Só Isso!, n. 4, dez. 2004, p. 01).

As internas, apesar da precariedade do sistema prisional, buscam maneiras de amenizar as mazelas do encarceramento e, de alguma forma, o trabalho, a escrita e a leitura se configuram até mesmo como estratégias de sobrevivência:

Aqui no TB é assim, onde umas andam pela cadeia vendo e ouvindo todo o tipo de gente e de situações, já outras estudam, trabalham ocupando o tempo e a mente de forma 
útil. Mas os dois casos funcionam como escape para não enlouquecermos pensando em nossos problemas e nossa dura realidade (Só Isso!, n. 10, set. 2006, p. 3).

Escrever na prisão, em condições em que viver é uma luta constante, se configura como uma forma de reconstruir a identidade perdida e dar continuidade à vida apesar das adversidades e clausura, das péssimas condições, e de "[...] los insultos, las vejaciones. Se escribe, em resumen, para poder seguir siendo persona” (Rubalcaba Pérez, 2005, p. $235)^{6}$.

Nas páginas do Só Isso! a subjetividade das internas ganha visibilidade, subjetividade esta que "é construída por meio de relações materiais, econômicas, interpessoais, efetivamente sociais e, em longo prazo, históricas, cujo efeito é a constituição de sujeitos como entidades autônomas e fontes confiáveis do conhecimento que provém do acesso ao real" (De Lauretis, 1992, p. 251-294 apud Arfuch, 2010, p. 119) e que no caso das mulheres que se abrigam na Talavera Bruce é marcada pelo sofrimento da vida em cárcere.

Tendo em vista que a condição da mulher no sistema sociocultural é marcada por processos históricos de opressão e discriminação, as mulheres privadas de liberdade carregam um estigma muito grande e que, normalmente, leva ao abandono total desses sujeitos. Assim, muitas, sentem-se absolutamente solitárias e, possivelmente, a escrita na prisão representa um grande desabafo, uma busca pelo equilíbrio emocional e um elo com mundo, que se torna extremamente significativo.

A leitura de diversos trechos do Só Isso! nos ajuda a pensar nas escritas como uma "tentativa desvairada de abolir a mais difícil das distâncias impostas entre um homem e o mundo" (Moraes, 2000, p. 55), que é a prisão.

Nesse sentido, o estudo desse impresso e das ilustrações nele contidas torna-se relevante na medida em que faz perceber o quanto a leitura e a escrita na prisão ajudam esses sujeitos a suportar a condição de privação de liberdade, permitindo ainda, uma melhor compreensão das práticas cotidianas das encarceradas, principalmente no que tange a uma realidade que possui suas especificidades e enfrenta grandes dificuldades ${ }^{7}$ :

\begin{abstract}
Muchas de esas escrituras transitan por la tenue línea que puede separar la libertad y la falta de esta. Aunque muchas vezes nacen de la necessidad de liberar lo más intimo de uno mismo o de exorcizar curtos pensamientos, tampoco os extraño que manifiesten los efectos de la censura intrìnseca a cualquier régimen de confinamiento o expresen la autocensura que quien escribe se impone en tales circunstancias (Castillo Gòmes; Sierra Blas, 2005, p. 12).
\end{abstract}

Os trechos do jornal aqui citados remetem a refletir acerca dos sentidos da escrita de si que se configura como instrumento de autoco- 
Imagens da Prisão Feminina

nhecimento, comunicação consigo mesmo e com outros e a busca por amenizar culpas e sofrimentos. Sendo essa escrita oriunda do encarceramento faz também compreender o que nos aponta Diego Navarro Bonilla (2005, p. 19): “[...] los prisioneiros como indivíduos que desarrolan su particular universo de lo escrito sorteando las dificultades y restricciones impuestas por la vida privada de libertad"8.

Se, a escrita na prisão se faz "[...] por intermédio dos conselhos e opiniões que se dão ao outro ela se constitui também uma certa maneira de cada um se manifestar a si próprio e aos outros. De certo modo a carta permite um 'face a face'” (Foucault, 1992, p. 149).

Nesse sentido, os relatos e ilustrações encontrados nesse jornal fazem emergir todas as dificuldades por que passam essas mulheres e, por meio destes, é possível perceber a necessidade de possíveis e novos caminhos para o plano institucional que lhes abriga na busca por soluções para os problemas que afetam esses sujeitos sociais tão estigmatizados.

Nessa perspectiva, é de extrema relevância pensar a escrita na prisão como uma forma de mulheres e homens apenados refletirem sobre sua condição de privação, suprindo suas demandas, dando voz às suas necessidades, constituindo um elo com o mundo além das grades. Desta forma, o direito ao ato de escrita na cadeia, torna-se e revestido de uma função social e educativa fundamental para a sobrevivência no cárcere.

\section{Algumas Considerações}

Possivelmente, a escrita e a leitura do jornal Só Isso! ajudam esses sujeitos a ocupar o tempo, manter o equilíbrio emocional, estabelecerem um elo com o mundo e suportarem o espaço frio da prisão (Mignot, 2002, p. 117).

Pensar a escrita e as ilustrações contidas no jornal é também uma forma de contribuir para que as demandas de mulheres apenadas sejam ouvidas, na medida em que se dá visibilidade às suas vozes e suas necessidades. Sendo assim, é possível suscitar, a partir do Só Isso! uma reflexão acerca da necessidade de propostas e políticas visando avanços na posição feminina, auxiliando o acesso social e minimizando as situações de discriminação.

Ao escrever e desenvolver ilustrações para o impresso as encarceradas expõem suas emoções, fragilidades, escolhas e aprendizados, já que "produzem um conhecimento sobre si, sobre os outros e o cotidiano, o qual revela-se através da subjetividade, da singularidade, das experiências e dos saberes" (Souza, 2008, p. 90).

Neste sentido, o Só Isso! se apresenta como um instrumento de grande importância para esses sujeitos, pois contempla a todas as en- 
carceradas de alguma forma, seja pertencendo a equipe e com isso conquistando um espaço de trabalho, seja como escritora e ou leitora, o que possibilita expressar sentimentos e diminuir as mazelas geradas pelo encarceramento.

O estudo sobre os sentidos da escrita de mulheres privadas de liberdade a partir desse impresso possibilita compreender discursos, relações e práticas. Faz-se necessária a valorização das apenadas, a conquista de autonomia, de espaço e de identidade social e, possivelmente, o impresso Só Isso! representa um avanço nesse sentido, possibilitando que, a partir da escrita, essas mulheres possam aliviar suas tensões, transmitam uma ideia de si, reinterpretem suas vidas na busca pela reconstrução de suas histórias, na medida em que refletem sobre sua condição atual de apenadas e projetam um futuro melhor para além dos muros e grades da prisão.

Assim como em outros jornais, por meio do Só Isso! "emergem 'vozes' que têm dificuldade em se fazerem ouvir noutros espaços sociais, tais como a academia ou o livro impresso" (Nóvoa, 2002, p. 31). Sendo assim, esse jornal demonstra o quanto essas mulheres se recusam a cumprir a invisibilidade imposta àqueles que estão em cumprimento de pena e se mostram, se fazem ouvir, pela palavra, pelo que expressam a partir do periódico aqui estudado.

Nesse sentido, é a partir das questões que envolvem o encarceramento feminino, e nas condições históricas pelas quais são percebidas, é que o estudo desse impresso se faz relevante no âmbito da história da educação. Apesar de não ser um jornal voltado para um público escolar, é possível pensá-lo como uma ação educativa, entendendo educação como um processo mais amplo, na medida em que discute valores, hábitos e comportamentos, reconhecendo a voz de um grupo que possui especificidades em seu modo de vida, e utiliza o recurso da escrita como uma forma de interagir com o cárcere.

Recebido em 16 de julho de 2012 Aprovado em 03 de dezembro de 2012

\section{Notas}

1 A imagem, sempre que bem selecionada, tem o poder de mostrar o que a palavra não pode expressar.

2 Não tive autorização para divulgar sua identidade.

3 No que tange ao patrocínio do impresso, verificamos empresas que se responsabilizam pela produção editorial, impressão e acabamento. Em todas as edições constam os nomes dessas empresas que são: In-Fólio - Produção Editorial, Gráfica e Programação, Shape Editoração Eletrônica e Grafitto Gráfica e Editora.

4 Disponível em: <www.observatoriodaimprensa.com.br>. Copyright Folha de São Paulo de 29 de junho de 2004. Acessado em: 17 maio 2010.

Educação \& Realidade, Porto Alegre, v. 38, n. 1, p. 137-153, jan./mar. 2013.

Disponível em: <http://www.ufrgs.br/edu_realidade> 
Imagens da Prisão Feminina

5 Este trabalho não discute todas as seções do impresso, tendo em vista a diversidade de temas.

6 Os insultos, os constrangimentos. Se escreve, em resumo, para seguir sendo pessoa.

7 Muitas dessas escritas transitam pela linha tênue que pode separar a liberdade e a falta desta. Estas muitas vezes nascem da necessidade de liberar o mais íntimo de si mesmo ou de exorcizar certos pensamentos, tampouco não é estranho perceber que manifestem os efeitos da censura intrínseca a qualquer regime de confinamento e expressem a autocensura que quem escreve se impões em tais circunstâncias.

8 Os prisioneiros como indivíduos que desenvolvem seu particular universo em seus escritos, trazendo as dificuldades e restrições impostas pela privação de liberdade.

\section{Referências}

ARFUCH, Leonor. O Espaço Biográfico: dilemas da subjetividade contemporânea. Rio de Janeiro: EdUERJ, 2010.

BONILLA, Diego Navarro. Archivos y Cultura Escrita Carcelaria: escribir y documentar la prisión desde el siglo XVI. In: SIERRA BLAS, Verônica; GÓMEZ, Castillo (Org.). Letras Bajo Sospecha: escritura y lectura en centros de internamiento. Alcalá: Ediciones Trea, 2005. P. 17-42.

CATANI, Denice Barbara; BASTOS, Maria Helena Camara (Org.). Educação em Revista: a imprensa periódica e a história da educação. São Paulo: Escrituras Editora, 2002.

CHARTIER, Roger. Formas e Sentido Cultura Escrita: entre distinção e apropriação. Campinas: Mercado de Letras, 2003.

CHARTIER, Roger. A História Cultural: entre práticas e representações. Lisboa: Difel, 2002.

CHIES, Luiz Antônio Bogo; VARELA, Adriana Batista. A Ambiguidade do Trabalho Prisional num Contexto de Encarceramento Feminino: o circulo vicioso da exclusão. In: XIII CONGRESSO BRASILEIRO DE SOCIOLOGIA. Sociedade Brasileira de Sociologia. 29 de maio a 01 de junho de 2007, UFPE, Recife (PE). GT30: Violência e Sociedade: segurança, controle e castigo. Anais... Pernambuco, 2007. Disponível em: < http://www.sbsociologia.com.br/portal/index. php?option=com_docman\&task $=$ cat_view\&gid=160\&Itemid=171 >. Acesso em: 07 jun. 2010.

CHIES, Luiz Antonio Bogo; BARROS, Ana Luisa Xavier. A Prisão dentro da Prisão: sínteses de uma visão sobre o encarceramento Feminimo na $5^{\mathrm{a}}$ Região Penitenciária do Rio Grande do Sul. Revista Brasileira de Ciências Criminais, São Paulo, ano 17, n. 79, p. 01-14, 2009.

DIAS, Márcia Hilsdorf. A escola Normal Paulista na ótica dos conservadores. In GONDRA, José. Dos Arquivos à Escrita da História: educação brasileira entre o império e a república. Bragança Paulista: EDUSF, 2002. P. 109-132.

FERNANDES, Ana Lúcia Cunha. O Impresso e a Circulação de Saberes Pedagógicos: apontamentos sobre a imprensa pedagógica na história da educação. In: Xavier, Libânia Nacif; Magaldi, Ana Maria Bandeira de Mello. IMPRESSOS e História da Educação: usos e destinos. Rio de Janeiro: 7letras, 2008. P. 15-29. 
FOUCAULT, Michel. O que É um Autor? Lisboa: Passagens, 1992.

GÓMEZ CASTILLO, Antonio; SIERRA BLAS, Verônica. Prólogo: entre la represión y la libertad. In: Letras Bajo Sospecha: escritura y lectura en centros de internamiento. Alcalá: Ediciones Trea, 2005. P. 11-16.

LEMGRUBER, Julita. Cemitério dos Vivos: análise sociológica de uma prisão de mulheres. Rio de Janeiro: Achiamé, 1999.

MIGNOT, Ana Chrystina Venâncio. Artesãos da Palavra: cartas a um prisioneiro político tecem redes de ideias e afetos. In: BASTOS, Maria Helena Camara; CUNHA, Maria Teresa Santos; MIGNOT, Ana Chrystina Venâncio (Org.). Destinos das Letras: história, educação e escrita epistolar. Passo Fundo: Ed. UFP, 2002. P. 115-116.

MORAES, Eliane Robert. A Cifra e o Corpo: as cartas de prisão do marquês de Sade. In: GALVÃO, Walnice Nogueira; GOTLIB, Nádia Battella. Prezado Senhor, Prezada Senhora - estudo sobre cartas. São Paulo: Companhia das Letras, 2000. P. 55-60.

NÓVOA, Antonio. A Imprensa de Educação e Ensino: concepção e organização do repertório português. In: CATANI, Denice; BASTOS, Maria Helena Camara. Educação em Revista: a imprensa periódica e a história da educação. São Paulo: Escrituras Editora, 2002. P. 11-31.

RUBACALBA PÉREZ, Carmen. Escribo aquello que no sabía decirle a nadie: la escritura en reclusión. In: SIERRA BLAS, Verônica; GÓMEZ, Castillo (Org.). Letras Bajo Sospecha: escritura y lectura en centros de internamiento. Alcalá: Ediciones Trea, 2005. P. 217-235.

SIERRA BLAS, Verônica. Aprender a Escribir Cartas: los manuales epistolares en la España contemporánea (1927-1945). Gijón: Trea, 2003.

SOARES, Bárbara Musumeci Soares; ILGENFRITZ, Iara. Prisioneiras: vida e violência atrás das grades. Rio de Janeiro: Garamond, 2002.

SOUZA, Elizeu Clementino de. Histórias de vida, escritas de si e abordagem experiencial. In: SOUZA, Elizeu Clementino de. Histórias de Vida e Formação de Professores. Rio de Janeiro: Quartet: FAPERJ, 2008. P. 87-101.

TAVARES, Daiane de Oliveira. Escritas Encarceradas: representações do universo prisional feminino nas páginas do jornal da Penitenciária Talavera Bruce. 2011. 141 f. Dissertação (Mestrado em Educação) - Programa de Pós-Graduação em Educação, Universidade do Estado do Rio de Janeiro, Rio de Janeiro, 2011.

Daiane de Oliveira Tavares é auxiliar de pesquisa do Observatório Jovem do Rio de Janeiro - Universidade Federal Fluminense, na cidade do Rio de Janeiro, no estado do Rio de Janeiro. Mestre em Educação pela UERJ. Especialista em Educação para jovens e adultos em situação de privação de liberdade. País: Brasil - Rio de Janeiro/ RJ.

E-mail: doliveiratavares@yahoo.com.br 